\title{
Delayed protective effect of telmisartan on lung ischemia/reperfusion injury in valve replacement operations
}

\author{
YONGFENG FAN, DAGUO ZHANG and DAOKANG XIANG \\ Department of Cardiac Surgery, The People's Hospital of Guizhou Province, Guiyang, Guizhou 550002, P.R. China
}

Received May 20, 2016; Accepted June 27, 2016

DOI: $10.3892 /$ etm.2016.3626

\begin{abstract}
The present study aimed to investigate the delayed protective effect of telmisartan on lung ischemic/reperfusion injury in patients undergoing heart valve replacement operations. In total, 180 patients diagnosed with rheumatic valve diseases were randomly divided into the telmisartan $(\mathrm{T})$, captopril (C) and placebo (P) groups. In the telmisartan group, the patients were pretreated with telmisartan $(1 \mathrm{mg} / \mathrm{kg} /$ day $)$, at the time period 96-48 $\mathrm{h}$ before the operation, whereas in the C group, the patients were treated with captopril $(1 \mathrm{mg} / \mathrm{kg} / \mathrm{day})$ at the time period $96-48 \mathrm{~h}$ prior to the operation control group. Each drug treatment group included a corresponding placebo treatment. The variables pulmonary vascular resistance (PVR) and $\mathrm{A}-\mathrm{aDO}_{2}$ were measured prior to $\mathrm{CPB}$ and at $1,3,6$ and $12 \mathrm{~h}$ after CPB. Pulmonary neutrophil (PMN) count in the left and right atrium blood as well as SOD malondialdehyde (MDA), NO, angiotensin II (AngII) value in the left atrium blood, were measured $30 \mathrm{~min}$ prior to and after CPB. The PVR parameters of the telmisartan and captopril groups were significantly lower than those of the placebo group $(\mathrm{P}<0.05)$. The $\mathrm{A}-\mathrm{aDO}_{2}$ values in the telmisartan and captopril groups were significantly lower than those in the placebo group at 1, 3 and $6 \mathrm{~h}$ following CPB treatment. The difference between the right and left atrium blood PMN was significantly lower in the telmisartan and captopril intervention groups compared to that in the placebo group $30 \mathrm{~min}$ following CPB treatment. The left atrium blood SOD and NO values were significantly higher, whereas the MDA value was significantly lower in the telmisartan group compared to the control group 30 min following CPB treatment. As for AngII, there was no difference between the $\mathrm{C}$ and $\mathrm{T}$ groups, compared with the $\mathrm{P}$ group. In the two groups $30 \mathrm{~min}$ after treatment with CPB, 24 patients experienced varying degrees of cough, with the telmisartan group showing a significant difference
\end{abstract}

Correspondence to: Dr Yongfeng Fan, Department of Cardiac Surgery, The People's Hospital of Guizhou Province, 83 East Zhongshan Road, Guiyang, Guizhou 550002, P.R. China

E-mail: fanyongfeng160422@163.com

Key words: telmisartan, lung, ischemia/reperfusion injury, nitric oxide
$(\mathrm{P}<0.05)$. The hospitalization time was compared in the three groups of patients and it was found to be significantly shorter in the telmisartan group than the captopril and placebo groups $(\mathrm{P}<0.05)$. In conclusion, it was found that for the time period 96-48 $\mathrm{h}$ before heart valve replacement operations telmisartan $(1 \mathrm{mg} / \mathrm{kg} /$ day $)$ delayed the protective effect on lung ischemia/reperfusion injury in patients with rheumatic valve diseases. The results of the present study indicated that the protective effect may be associated with the increment of endogenetic NO and the enhanced ability against lipid peroxidation.

\section{Introduction}

Mitral valve replacement surgery is one of the main surgical methods in the treatment of rheumatic valvular disease (1). During the operation, deep hypothermia is required, and the cardiopulmonary bypass is used to carry out respiratory and circulatory support (2). Extracorporeal circulation as a non-physiological circulation mode can cause the pathological and physiological changes of pulmonary vessels and pulmonary parenchyma after operation in patients who received mitral valve replacement surgery (3). Postoperative acute lung injury is relatively common and is capable of inducing serious respiratory distress syndrome, seriously affecting the patient's quality of life during peri-operation (4). Previous studies on rats have shown that, lung ischemic preconditioning treatment can significantly improve the postoperative $\mathrm{PaO}_{2}$ level, and significantly reduce pulmonary arterial pressure, lung wet/dry weight ratio and the level of malondialdehyde (MDA) (4), indicating that ischemic preconditioning treatment can reduce lung ischemia/reperfusion injury in these animal models (5). Although the underlying mechanisms of lung ischemia/reperfusion injury are not fully elucidated, it is thought to involve the activation of TRPC6 channels (6).

Previous findings indicated that the process of pulmonary ischemia/reperfusion injury can be effectively improved after the use of ACEI before cardiopulmonary bypass surgery in patients with valve disease (7). However, after use of captopril, the metabolism of bradykinin (BK) decreased and accumulated in the blood, resulting in lung activation (8). Patients experience varying degrees of complications, while other patients exhibit respiratory symptoms such as bleeding (9), which is not conducive to postoperative wound healing. Telmisartan is a new type of antihypertensive drug that acts as a specific 
angiotensin II (AngII) type 1 receptor (AT1) antagonist (10). Telmisartan antagonizes the binding of angiotensin II receptor to the AT1 receptor subtype. In the absence of an agonist effect, telmisartan can be selectively combined with the AT1 receptor with a lasting effect. Compared with ACEI, ARB can significantly reduce respiratory secretions (12).

In the present study, 180 cases of patients with rheumatic heart disease were selected to undergo mitral valve replacement. Prior to extracorporeal circulation, the patients were administered telmisartan, captopril and placebo pretreatment to observe the condition of postoperative ischemia reperfusion injury, and the clinical efficacy of telmisartan and captopril was subsequently examined.

\section{Subjects and methods}

Subjects and groups. Between March October, 2013 to March, 2015, 180 patients were diagnosed via clinical symptoms, signs and echocardiogram as having rheumatic heart disease. The patients included 132 cases of single valve replacement, and 48 cases of double valve replacement. The patients were randomly assigned to the placebo $(n=60)$, captopril preconditioning $(\mathrm{n}=60)$ and telmisartan preconditioning $(n=60)$ groups. Detailed information of the enrolled patients is shown in Table I.

The present study was approved by the ethics committee of The People's Hospital of Guizhou (Guizhou, China).

Inclusion and exclusion criteria. The inclusion criteria for the study were: i) NYHA: grades II-III; ii) diagnosis of rheumatic heart disease via clinical symptoms, signs and echocardiography. The exclusion criteria for the study were: 3 months prior to operation, a history of activity of rheumatic disease, infection, heart failure, and history of unconsciousness; iii) within 2 weeks of surgery, the patients were administered ACEIs or ARBs. The perioperative administration of nitrates included: iv) patients and family members cannot cooperate with the inspection, and v) mental illness or consciousness disorder.

\section{Pretreatments}

Captopril group. Captopril ( $1 \mathrm{mg} / \mathrm{kg} /$ day) was administered 96-48 $\mathrm{h}$ before surgery. The blood pressure, heart rate, heart rate and subjective discomfort were observed prior to and after patients were administered the drug.

Telmisartan group. Telmisartan $(1 \mathrm{mg} / \mathrm{kg} / \mathrm{day})$ was administered $96-48 \mathrm{~h}$ before surgery. The parameters investigated were identical to those of the captopril group.

Placebo group. A placebo with similar size, color and shape was administered as indicated above.

Measurement and calculations of pulmonary vascular resistance. Pulmonary vascular resistance (PVR) was calculated using the equation: [mean arteriral pressure (MAP) - pulmonary cap wedge pressure (PCWP)] x 79.92 cardiac output (CO). The alveolar-arterial oxygen gradient was calculated as:

$\mathrm{A}-\mathrm{aDO}_{2}=\mathrm{FiO}_{2}\left(\mathrm{P}_{\mathrm{atm}}-47 \mathrm{mmHg}\right)-\mathrm{PaCO}_{2}-\mathrm{PaO}_{2}$

The correction value was measured as: $\mathrm{Hb}$ (before $\mathrm{CPB} / \mathrm{Hb}$ (the specimen) $\mathrm{x}$ measured value.
Table I. Patient information.

\begin{tabular}{lccc}
\hline Groups & No. of males & No. of females & Age (years) \\
\hline Telmisartan & 27 & 33 & $52.4 \pm 12.3$ \\
Captopril & 25 & 35 & $55.6 \pm 7.2$ \\
Placebo & 32 & 28 & $58.3 \pm 12.8$ \\
\hline
\end{tabular}

Statistical analysis. SPSS 19.0 software (Chicago, IL, USA) was used for statistical analysis in the present study. Data were presented as (mean $\pm \mathrm{SD}$ ). Quantitative data were compared by analysis of variance. Qualitative data were compared by the Chi-square test. The Fisher's exact test method was used to calculate the exact probability. The correlation between postoperative lymphocyte changes and biliary tract infection were evaluated by the logistic model. The difference was statistically significant when $\mathrm{P}<0.05$.

\section{Results}

General clinical situation of three groups of patients. Between October, 2013 to March, 2015, 180 patients were diagnosed via clinical symptoms, signs and echocardiogram as having rheumatic heart disease. The patients included 132 cases of single valve replacement, and 48 cases of double valve replacement. The patients were randomly assigned to the placebo $(n=60)$, captopril preconditioning $(n=60)$ and telmisartan preconditioning ( $\mathrm{n}=60)$ groups. The patient's age, body weight, cardiac function classification, cardiopulmonary bypass time, and vena cava blocking time were recorded and analyzed (Table II).

PVR in the three groups. Preoperative PVR was higher, and compared with PVR measured at $1,3,6$ or $12 \mathrm{~h}$ prior to CPB treament, there was no significant difference in the groups $(\mathrm{P}>0.05)$. After valve replacement, the PVR of the captopril and telmisartan groups was significantly decreased $(\mathrm{P}<0.05)$ at each time-point. However, no significant difference was found between the captopril and telmisartan groups $(\mathrm{P}>0.05)$ (Table III).

Measurement of the level of secondary variables SOD, $M D A$, AngII and NO in left atria blood before and $30 \mathrm{~min}$ after treatment with $C P B$. The left atrium blood SOD and NO value was significantly higher, whereas the MDA value was significantly lower in the telmisartan group than that in the placebo group $30 \mathrm{~min}$ after treatment with CPB. As for AngII, there was no difference between the captopril and telmisartan groups, compared with the placebo group $30 \mathrm{~min}$ after CPB (Table IV).

Complications and hospital time. In the present study, we found that, 24 patients experienced varying degrees of cough in the captopril group, whereas no symptoms of cough were evident in the telmisartan group $(\mathrm{P}<0.05)$. Hospitalization time was compared for the three groups of patients and it was found to be significantly shorter in the telmisartan group 
Table II. Data and variables regarding the three groups of patients (mean $\pm \mathrm{SD}$ ).

\begin{tabular}{|c|c|c|c|c|c|c|}
\hline Group & Case no. & Age (years) & Body weight (kg) & NYHA (II/III) & $\mathrm{CPB}(\min )$ & $\mathrm{VC}(\min )$ \\
\hline Telmisartan & 60 & $0.52 .4 \pm 12.3$ & $68.3 \pm 21.9$ & $29 / 31$ & $72.3 \pm 12.6$ & $51.2 \pm 12.7$ \\
\hline Captopril & 60 & $55.6 \pm 7.2$ & $66.4 \pm 27.1$ & $28 / 32$ & $77.8 \pm 8.5$ & $53.2 \pm 22.1$ \\
\hline Placebo & 60 & $58.3 \pm 12.8$ & $63.4 \pm 19.8$ & $34 / 26$ & $74.8 \pm 19.7$ & $52.6 \pm 13.9$ \\
\hline F-value & - & 0.27 & 0.62 & 0.33 & 0.48 & 0.99 \\
\hline P-value & - & 0.37 & 0.44 & 0.68 & 0.55 & 0.17 \\
\hline
\end{tabular}

NYHA, New York Heart Association. VC, vena cava blocking time.

Table III. PVR in the three groups.

\begin{tabular}{lcccccccc}
\hline Group & Case no. & Before CPB & 1 h after CPB & 3 h after CPB & $6 \mathrm{~h}$ & $12 \mathrm{~h}$ & F-value & P-value \\
\hline Telmisartan & 60 & $331.6 \pm 25.7$ & $231.7 \pm 45.3$ & $182.7 \pm 42.8$ & $92.3 \pm 29.6$ & $122.4 \pm 23.6$ & 31.5 & 0.002 \\
Captopril & 60 & $348.9 \pm 12.6$ & $252.6 \pm 23.8^{\mathrm{a}}$ & $184.5 \pm 33.6^{\mathrm{a}}$ & $93.2 \pm 22.8$ & $121.4 \pm 22.5$ & 48.3 & 0.001 \\
Placebo & 60 & $349.3 \pm 12.8$ & $261.6 \pm 19.4$ & $212.6 \pm 48.6$ & $134.8 \pm 26.9$ & $129.4 \pm 12.9$ & 39.1 & 0.001 \\
F-value & - & 0.33 & 0.41 & 2.57 & 14.7 & 21.2 & - \\
P-value & - & 0.37 & 0.33 & 0.02 & 0.01 & 0.01 & - \\
\hline
\end{tabular}

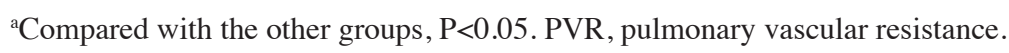

Table IV. Measurement of the level of secondary variables SOD, MDA, AngII and NO in left atria blood before and 30 min after treatment with CPB.

\begin{tabular}{|c|c|c|c|c|c|c|}
\hline & Groups & Case no. & Before CPB & $1 / 2 \mathrm{~h}$ after $\mathrm{CPB}$ & F-value & P-value \\
\hline \multirow[t]{3}{*}{ SOD (IU/ml) } & Telmisartan & 60 & $131.6 \pm 15.7$ & $171.7 \pm 49.3$ & 21.5 & 0.002 \\
\hline & Captopril & 60 & $138.9 \pm 12.8$ & $172.6 \pm 22.8$ & 58.3 & 0.001 \\
\hline & Placebo & 60 & $134.9 \pm 14.8$ & $141.6 \pm 16.4$ & 19.1 & 0.010 \\
\hline F-value & & - & 0.33 & 0.41 & - & - \\
\hline P-value & & - & 0.37 & 0.33 & - & - \\
\hline \multirow[t]{3}{*}{$\operatorname{MDA}(\mathrm{nmol} / \mathrm{ml})$} & Telmisartan & 60 & $2.28 \pm 0.14$ & $3.38 \pm 1.02$ & 4.37 & 0.017 \\
\hline & Captopril & 60 & $2.39 \pm 0.21$ & $3.25 \pm 0.97$ & 5.56 & 0.011 \\
\hline & Placebo & 60 & $2.52 \pm 0.17$ & $4.63 \pm 1.25$ & 2.71 & 0.026 \\
\hline F-value & & - & 0.39 & 12.5 & - & - \\
\hline P-value & & - & 0.66 & 0.01 & - & - \\
\hline \multirow[t]{3}{*}{ AngII (pg/ml) } & Telmisartan & 60 & $77.4 \pm 12.81$ & $168.4 \pm 10.9$ & 2.38 & 0.021 \\
\hline & Captopril & 60 & $80.4 \pm 13.9$ & $166.4 \pm 12.8$ & 1.98 & 0.024 \\
\hline & Placebo & 60 & $81.2 \pm 10.6$ & $189.7 \pm 21.3$ & 1.28 & 0.031 \\
\hline F-value & & - & 0.62 & 21.4 & - & - \\
\hline P-value & & - & 0.39 & 0.02 & - & - \\
\hline \multirow[t]{3}{*}{$\mathrm{NO}(\mu \mathrm{mol} / \mathrm{l})$} & Telmisartan & 60 & $38.4 \pm 11.3$ & $78.2 \pm 22.4$ & 10.29 & 0.018 \\
\hline & Captopril & 60 & $35.7 \pm 14.8$ & $74.4 \pm 23.5$ & 11.33 & 0.014 \\
\hline & Placebo & 60 & $36.8 \pm 10.9$ & $43.8 \pm 18.7$ & 9.82 & 0.016 \\
\hline \multirow[t]{3}{*}{$\mathrm{PMN}\left(\mathrm{x} 10^{9} / 1\right)$} & Telmisartan & 60 & $0.28 \pm 0.56$ & $3.72 \pm 1.15$ & 7.87 & 0.023 \\
\hline & Captopril & 60 & $0.35 \pm 0.76$ & $2.41 \pm 1.73$ & 6.59 & 0.032 \\
\hline & Placebo & 60 & $0.44 \pm 0.21$ & $9.33 \pm 0.29$ & 11.33 & 0.001 \\
\hline$F$ value & & & 0.38 & 9.94 & & \\
\hline$P$ value & & & 0.72 & 0.002 & & \\
\hline
\end{tabular}

MDA, malondialdehyde. 
Table V. Complications and hospital time.

\begin{tabular}{lccc}
\hline Groups & Case no. & Cough & Hospital time (days) \\
\hline Telmisartan & 60 & 0 & $7.87 \pm 1.3$ \\
Captopril & 60 & 24 & $9.36 \pm 2.82$ \\
Placebo & 60 & 2 & $10.6 \pm 1.44$ \\
P-value & - & 0.01 & 0.01 \\
\hline
\end{tabular}

compared to the captopril and placebo groups. The difference was statistically significant $(\mathrm{P}<0.05)$ (Table V).

\section{Discussion}

During CPB, a large number of oxygen-free radicals are generated in the lung following ischemia/reperfusion leading to the leukocyte aggregation and activation of the complement (1). This is an important mechanism leading to CPB after lung injury (2-4). Therefore, the protective effect of lung ischemia reperfusion injury following cardiopulmonary bypass has attracted considerable attention (5). PMN aggregation is important in the pathogenesis of acute lung injury after cardiopulmonary bypass (11). Neutrophil aggregation in the lung releases a variety of enzymes and generates a large number of oxygen-free radicals by degranulation. Additionally, neutrophil aggregation induces damage to endothelial cells and strong lipid peroxidation, resulting in lung injury $(6,12)$. In the present study, the PMN levels in the three groups of patients after 30 min of CPB were significantly higher than those prior to treatment with $\mathrm{CPB}(\mathrm{P}<0.05)$.

After CPB, the patient has a certain degree of PMN aggregation. Subsequent to pretreatment with captopril and telmisartan, the difference was decreased compared to the placebo group. This difference was statistically significant $(\mathrm{P}<0.05)$. The results indicated that preoperative preconditioning has a positive effect on reducing the aggregation of $\mathrm{PMN}$ in the lung after CPB.

Captopril, a compound that belongs to the angiotensin-converting enzyme inhibitors mainly affects the renin-angiotensin system (RAS) (9). Captopril inhibits the release of BK, which in turn, inhibits the increase of endogenous BK. At present, BK acts as a trigger of pretreatment. Additionally, BK acts on the endothelium of the BK- $\beta 2$ receptor, which induces a rapid and transient translocation of protein kinase $\mathrm{C}$, triggering the release of endogenous $\mathrm{NO}$ and PGI2 $(8,13)$. NO is capable of inhibiting the adhesion of PMN and endothelial cells, promotes the relaxation of blood vessels and reduces vascular permeability. In the present study, following pretreatment with captopril and telmisartan, the NO in left atrial blood was significantly higher than that in the placebo group $(\mathrm{P}<0.05)$.

In the absence of NO releases, cGMP levels were increased, which decreased the adhesion and aggregation of neutrophils in the lung, thereby reducing lung injury. Telmisartan is an angiotensin receptor inhibitor that binds with the AngII receptor with AT I receptor subtype. Previous findings suggest that, telmisartan has no agonist effect on AT I receptor site $(14,15)$. Therefore, telmisartan can be combined with AT receptor for a relatively long period of time. In addition to other receptors, such as AT2, telmisartan showed no affinity. Telmisartan does not inhibit renin, nor block ion channels, and does not exert an inhibitory effect on angiotensin-converting enzyme. In the present study, we found that in the captopril group, 24 patients experienced varying degrees of cough symptoms, whereas in the telmisartan group, no obvious cough symptoms were evident $(\mathrm{P}<0.05)$. Hospitalization time was compared in the three groups of patients and was significantly shorter in the telmisartan group compared to the captopril and placebo groups, with the difference being statistically significant $(\mathrm{P}<0.05)$.

In conclusion, the use of telmisartan as a pretreatment drug prior to treatment with CPB is recommended in the prevention of pulmonary ischemia and reperfusion injury. The effect of telmisartan and captopril in the prevention of pulmonary ischemia reperfusion injury was virtually identical. However, telmisartan significantly improved the cough symptoms and other adverse reactions of captopril in protecting lung ischemia reperfusion injury.

\section{References}

1. Yiu KH, Wong A, Pu L, Chiang MF, Sit KY, Chan D, Lee HY, Lam YM, Chen Y, Siu CW, et al: Prognostic value of preoperative right ventricular geometry and tricuspid valve tethering area in patients undergoing tricuspid annuloplasty. Circulation 129: 87-92, 2014.

2. Ferrari RS and Andrade CF: Oxidative stress and lung ischemia- reperfusion injury. Oxid Med Cell Longev 2015: 590987, 2015.

3. Deng C, Zhai Z, Wu D, Lin Q, Yang Y, Yang M, Ding H, Cao X, Zhang $Q$ and Wang C: Inflammatory response and pneumocyte apoptosis during lung ischemia-reperfusion injury in an experimental pulmonary thromboembolism model. J Thromb Thrombolysis 40: 42-53, 2015.

4. Allen BS, Ko Y, Buckberg GD and Tan Z: Studies of isolated global brain ischaemia: III. Influence of pulsatile flow during cerebral perfusion and its link to consistent full neurological recovery with controlled reperfusion following $30 \mathrm{~min}$ of global brain ischaemia. Eur J Cardiothorac Surg 41: 1155-1163, 2012.

5. Granger DN and Kvietys PR: Reperfusion injury and reactive oxygen species: the evolution of a concept. Redox Biol 6: 524-551, 2015.

6. Weissmann N, Sydykov A, Kalwa H, Storch U, Fuchs B, Mederos y Schnitzler M, Brandes RP, Grimminger F, Meissner M, Freichel M, et al: Activation of TRPC6 channels is essential for lung ischaemia-reperfusion induced oedema in mice. Nat Commun 3: 649, 2012.

7. Porter AJ, Pillidge K, Grabowska EM and Stanford SC: The angiotensin converting enzyme inhibitor, captopril, prevents the hyperactivity and impulsivity of neurokinin-1 receptor gene 'knockout' mice: sex differences and implications for the treatment of attention deficit hyperactivity disorder. Eur Neuropsychopharmacol 25: 512-521, 2015.

8. Elder DH, Wei L, Szwejkowski BR, Libianto R, Nadir A, Pauriah M, Rekhraj S, Lim TK, George J, Doney A, et al: The impact of renin-angiotensin-aldosterone system blockade on heart failure outcomes and mortality in patients identified to have aortic regurgitation: a large population cohort study. J Am Coll Cardiol 58: 2084-2091, 2011.

9. Nadir MA, Wei L, Elder DH, Libianto R, Lim TK, Pauriah M, Pringle SD, Doney AD, Choy AM, Struthers AD, et al: Impact of renin-angiotensin system blockade therapy on outcome in aortic stenosis. J Am Coll Cardiol 58: 570-576, 2011.

10. Sonsalla PK, Coleman C, Wong LY, Harris SL, Richardson JR, Gadad BS, Li W and German DC: The angiotensin converting enzyme inhibitor captopril protects nigrostriatal dopamine neurons in animal models of parkinsonism. Exp Neurol 250: 376-383, 2013 
11. Eltzschig HK and Eckle T: Ischemia and reperfusion - from mechanism to translation. Nat Med 17: 1391-1401, 2011.

12. Lancellotti P, Tribouilloy C, Hagendorff A, Popescu BA, Edvardsen T, Pierard LA, Badano L and Zamorano JL; Scientific Document Committee of the European Association of Cardiovascular Imaging: Recommendations for the echocardiographic assessment of native valvular regurgitation: an executive summary from the European Association of Cardiovascular Imaging. Eur Heart J Cardiovasc Imaging 14: 611-644, 2013.

13. Lu L, Xu K, Zhang LJ, Morelli J, Krazinski AW, Silverman JR, Schoepf UJ and Lu GM: Lung ischaemia-reperfusion injury in a canine model: dual-energy CT findings with pathophysiological correlation. Br J Radiol 87: 20130716, 2014.
14. Kalogeris T, Baines CP, Krenz M and Korthuis RJ: Cell biology of ischemia/reperfusion injury. Int Rev Cell Mol Biol 298: 229-317, 2012.

15. Leavitt BJ, Baribeau YR, DiScipio AW, Ross CS, Quinn RD, Olmstead EM, Sisto D, Likosky DS, CochranRP, Clough RA, et al; Northern New England Cardiovascular Disease Study Group: Outcomes of patients undergoing concomitant aortic and mitral valve surgery in northern new England. Circulation 120 (Suppl): S155-S162, 2009. 